\title{
Analisa Fasilitas Kerja, Pelatihan dan Kedisiplinan Terhadap Kinerja Karyawan PT. Centrayasa Megatamacipta
}

\author{
Raston Sitio ${ }^{1}$ \\ Universitas Mpu Tantular \\ rastonsitio65@gmail.com
}

\begin{abstract}
Abstrak
Penelitian ini untuk menganalisis pengaruh fasilitas kerja, pelatihan, dan kedisiplinan terhadap kinerja karyawan PT.Centrayasa Megatamacipta. Dalam mengatasi masalah Sumber Daya Manusia (SDM) harus memperhatikan perkembangan maka kinerja yang dihasilkan agar menunjang kemajuan perusahaan. Metode pengumpulan data dalam penelitian ini adalah, observasi dan studi dokumentasi.Populasi penelitian ini berjumlah 92 responden pada PT. Centrayasa Megatamacipta bagian teknisi dengan jumlah sampel ditetapkan menggunakan metode sampling jenuh. Analisis yang digunakan meliputi uji t,uji f, analisis regresi berganda linier dan Koefisien determinan (R2) dengan menggunakan Software SPSS 23. Hasil penelitian menunjukan bahwa hasil t-hitung fasilitas kerja 0.041 atau $4.1 \%$ mempengaruhi kinerja karyawan PT. Centrayasa Megatamacipta,sementara t-hitung pelatihan 3.183 atau 318\% mempengaruhi kinerja karyawan PT. Centrayasa Megatamacipta dan t-hitung kedisiplinan 4.170 atau $417 \%$ mempengaruhi kinerja karyawan PT. Centrayasa Megatamacipta dengan nilai t-tabel sebesar 1,987 dan nilai koefisien determinasi $\mathrm{R}^{2}$ sebesar $0.382(38,3 \%)$ fasilitas kerja, pelatihan dan kedisiplinan berpengaruh terhadap kinerja karyawan PT. Centrayasa Megatamacipta secara simultan sebesar $38,2 \%$ dan sisanya sebesar $61,8 \%$ dipengaruhi oleh faktor lain yang belum diteliti.
\end{abstract}

Kata Kunci: Fasilitas Kerja, Pelatihan, dan Kedisiplinan Terhadap Kinerja Karyawan

\section{Pendahuluan}

Latar Belakang Masalah Era globalisasi perusahaan harus memaksimalkan kinerja karyawan melalui pelatihan agar mencapai hasil yang optimal.Untuk menunjang hal tersebut,fasilitas kerja,pelatihan, dan kedisiplinan sangat berperan penting. Fasilitas kerja yang baik dengan alat yang sesuai mendukung kinerja karyawan lebih kondusif,pelatihan dan kedisiplinan membuat pekerjaan lebih efektif, efisien, berkualitas sehingga perusahaan mampu bersaing. PT. Centrayasa Megatamacipta perusahaan yang bergerak dibidang jasa pelatihan pemeliharaan gedung dan apartemen.Pelatihan diberikan sesuai kebutuhan gedung, untuk apartemen mengutamakan pelatihan kelistrikan, maintenance AC dan maintenance Pompa, Mall dan gedung perkantoran diutamakan pada AHU dan FCU. (Hasibuan, 2014) menjelaskan kedisiplinan adalah fungsi operasional ke enam personalia, semakin tinggi disiplin karyawan semakin tinggi hasil produktifitas perusahaan.Kinerja karyawan adalah hasil kerja secara kualitas dan kuantitas yang dicapai seorang karyawan melaksanakan tugasnya.

\footnotetext{
${ }^{1}$ Korespondensi: Raston Sitio, Universitas Mpu Tantular, Jalan Cipinang Besar No.2. 68 Jakarta Timur 13410, Indonesia. rastonsitio65@gmail.com.
} 


\section{Literature Review}

\section{Pengertian Manajemen Sumberdaya Manusia}

Manajemen sumber daya manusia adalah perencanaan, pengorgnisasian, pengarahan, pengawasan atas pengadaan, pengembangan, kompensasi, pengintegrasian dan pemutusan kerja untuk memaksimalkan keuntungan perusahaan

\section{Pengertian Kinerja}

Kinerja adalah adalah gambaran pencapaian pelaksanaan program, kebijaksanaan dalam mewujudkan sasaran, tujuan, misi dan visi suatu organisasi (Sitio, 2019). Jika kinerja perusahaan menurun maka harus dilakukan analisa terhadap sumber-sumber daya yang dimiliki agar dapat mengetahui penyebanya. (Fred \& Brigham, 2011) analisa yang dilakukan mencakup, pembandingan kinerja perusahaan dengan perusahaan lain dalam industri yang sama dan evaluasi kecenderungan posisi pertumbuhan laba perusahaan sepanjang waktu. Fasilitas kerja adalah alat dan sarana yang digunakan untuk mempermudah pekerjaan agar dapat dikerjakan sesuai dengan harapan dan dapat mencapai target yang ditentukan. Untuk mencapai target yang tinggi, diperlukan alat dan sarana yang baik dan berkualitas yang sesuai dengan kebutuhan untuk mempermudah pekerjaan. Selain alat yang baik,manusia yang mengerjakanya harus dilatih agar trampil dalam menggunakan alat tersebut serta mempunyai kedisiplinan yang tinggi.Kedisiplinan adalah kesadaran dan kesediaan seseorang mentaati peraturan dan norma-norma yang berlaku diperusahaan (Hasibuan, 2014). Menjelaskan bahwa kedisiplinan adalah perilaku seseorang yang sesuai dengan peraturan, prosedur kerja yang ada

\section{Metode Penelitian}

1. Desain Penelitian

Desain yang digunakan penelitian adalah deskriftif korelasi untuk menggambarkan hubungan dan pengaruh antara variabel bebas dengan variable terikatnya ( (Ghozali, 2016). Pendekatan penelitian ini adalah kualitatif mengukur variable bebas dan variable terkait dengan menggunakan skala Likert, jawaban ditabulasi dan diolah melalui analisis statistik.

2. Bagan Alir Penelitian

Metode penelitian ini adalah seperti diagram alir dibawah ini:

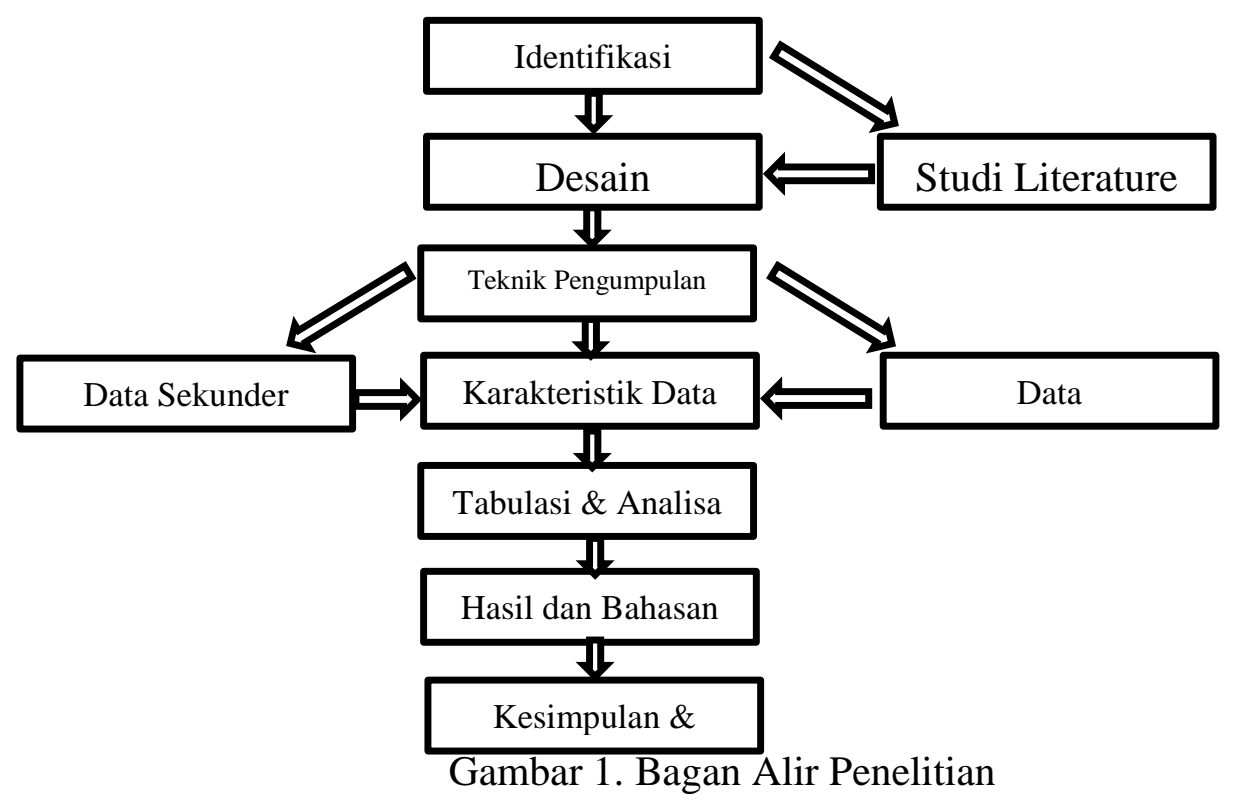


3. Teknik Pengumpulan Data

Teknik pengumpulan data penelitian ini dilakukan dengan dua cara : data primer dilkakukan dengan menyebarkan kuesioner kepada responden secara acak dan data sekunder dilakukann dengan studi literature pada sumber-sumber yang terkait. Populasi penelitian ini seluruh karyawan PT. Centrayasa Megatamacipta yang terletak di Tanjung Duren Jakarta Barat, yang berjumlah 120 karyawan. Populasi adalah wilayah generasi yang terdiri atas : obyek/subyek yang mempunyai kualitas dan karakteristik tertentu yang ditetapkan oleh peneliti untuk dipelajari kemudian ditarik kesimpulan (Sugiyono,2016).Teknik pengambilan sampling penelitian ini menggunakan rumus Slovin dengan tingkat kesalahan 5\% $(\alpha=5)$ atau df 95\% diperoleh jumlah sample sebanyak 92 responden.

Keterangan

$$
n=N /\left(1+N(e)^{2}\right.
$$

$\mathrm{n} \quad=$ Jumlah Sampel

$\mathrm{N} \quad=$ Jumlah Populasi

$\mathrm{E} \quad=$ Persentase kelonggaran ketelitian kesalahan penempatan sampel

$$
n=\frac{120}{1+120(0,05)^{2}}=\frac{120}{1+120(0,0025)}=\frac{120}{1+0.3}=\frac{120}{1.3}=92,307
$$

4. Hipotesis Penelitian:

Bagian ini adalah penjelasan singkat hipotesis penelitian dan dibagi menjadi empat yang bertujuan :

a. Menemukan masalah fasilitas kerja pada PT.Centrayasa Megatamacipta menunjang kinerja karyawan $(\mathrm{H} 1)$

b. Menemukan masalah pelatihan pada PT. Centrayasa Megatamacipta menunjang kinerja karyawan. (H2)

c. Menemukan masalah kedisiplinan pada PT. Centrayasa Megatamacipta menunjang kinerja karyawan (H3)

d. Menemukan masalah fasilitas kerja,pelatihan dan kedisiplinan pada PT. Centrayasa Megatamacipta menunjang kinerja karyawan (H4)

Kriteria Pengambilan Keputusan adalah hipotesis nol ditolak pada tingkat signifikansi $\alpha=5 \%$ (0.05) jika hasil test statistic >sig. 0.05

$\mathrm{H} 1=0$ Tidak terdapat hubungan dan pengaruh fasilitas kerja terhadap kinerja karyawan PT.Centrayasa Megatamacipta

H1 $\neq 0$ Terdapat hubungan dan pengaruh fasilitas kerja terhadap kinerja karyawan PT.Centrayasa Megatamacipta

$\mathrm{H} 2=0$ Tidak terdapat hubungan dan pengaruh fasilitas kerja terhadap kinerja karyawan PT.Centrayasa Megatamacipta

$\mathrm{H} 2 \neq 0$ Terdapat hubungan dan pengaruh fasilitas kerja terhadap kinerja karyawan PT.Centrayasa Megatamacipta

H3 = 0 Tidak terdapat hubungan dan pengaruh fasilitas kerja terhadap kinerja karyawan PT.Centrayasa Megatamacipta

H3 $\neq 0$ Terdapat hubungan dan pengaruh fasilitas kerja terhadap kinerja karyawan PT.Centrayasa Megatamacipta

\section{Kerangka Berpikir}




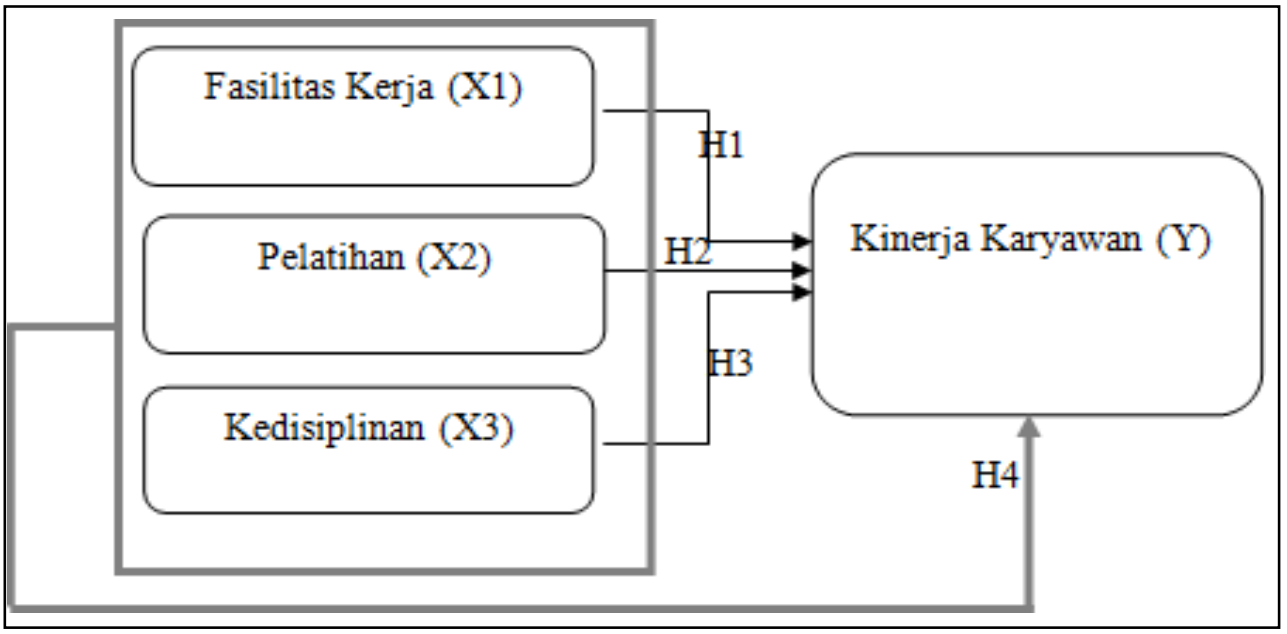

Gambar 2. Kerangka Berpikir

\section{Hasil}

1. Uji Validitas Nilai Person Correlation

Tabel 1. Hasil Uji Validitas Variabel X1,X2,X3,Y

\begin{tabular}{|c|l|l|l|l|l|}
\hline $\begin{array}{c}\text { No. } \\
\text { Item }\end{array}$ & r-tabel & $\begin{array}{l}\text { r-hitung } \\
\text { (X1) }\end{array}$ & $\begin{array}{l}\text { r-hitung } \\
\text { (X2) }\end{array}$ & $\begin{array}{l}\text { r-hitung } \\
\text { (X3) }\end{array}$ & $\begin{array}{l}\text { r-hitung } \\
\text { (Y) }\end{array}$ \\
\hline 1 & 0,207 & 0,471 & 0,697 & 0,652 & 0,516 \\
\hline 2 & 0,207 & 0,342 & 0,683 & 0,737 & 0,551 \\
\hline 3 & 0,207 & 0,632 & 0,635 & 0,476 & 0,568 \\
\hline 4 & 0,207 & 0,648 & 0,651 & 0,446 & 0,545 \\
\hline 5 & 0,207 & 0,674 & 0,510 & 0,525 & 0,410 \\
\hline 6 & 0,207 & 0,531 & 0,459 & 0,758 & 0,693 \\
\hline 7 & 0,207 & 0,666 & 0,657 & 0,724 & 0,564 \\
\hline 8 & 0,207 & 0,670 & 0,635 & 0,572 & 0,605 \\
\hline
\end{tabular}

Tabel 1 memperlihatkan hasil uji validitas semua item pertanyaan diperoleh nilai r-hitung paling rendah 0.342 dan paling tinggi 0.758 rata-rata diatas nilai r-tabel 0.207.Dengan demikian semua item pertanyaan adalah valid

2. Uji Reliabilitas

Tabel 2. Hasil Uji Reliabilitas Alpha >0,70

\begin{tabular}{|l|c|c|c|c|}
\hline \multicolumn{1}{|c|}{ Variable } & $\begin{array}{c}\text { Fasilitas } \\
\text { Kerja (X1) }\end{array}$ & Pelatihan (X2) & $\begin{array}{c}\text { Kedisiplinan } \\
\text { (X3) }\end{array}$ & Kinerja (Y) \\
\hline Fasilitas Kerja (X1) & 0,826 & & & \\
\hline Pelatihan (X2) & & 0,766 & & \\
\hline Kedisiplinan (X3) & & & 0,805 & \\
\hline Kinerja (Y) & & & & 0,744 \\
\hline
\end{tabular}

Tabel 2 hasil uji reliabilitas diperoleh nilai Cronb ach's Alpha lebih besar dari batas minimal yang dipersyaratkan yakni 0.70, dengan demikina semua butir pertanyaan X1, X2, X3 dan X4 adalah reliebel 
3. Uji Normalitas

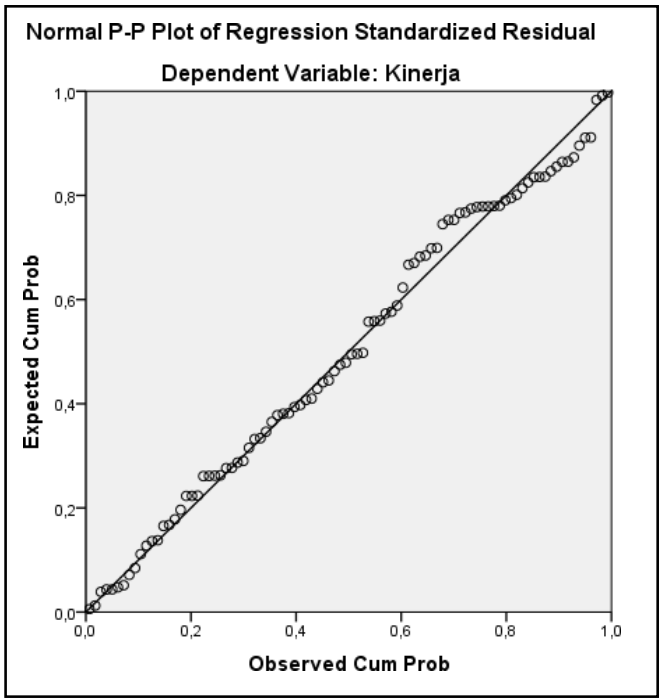

Gambar 3. Hasil Uji Normalitas Data

Gambar 3 Hasil uji normalitas data tampilan grafik histrogram normal plot titik-titk menyebar disekitar garis diagonal dan mengikuti arah garis diagonal menunjukan pola distribusi normal maka model regresi yang digunakan memenuhi asumsi normalitas dan besarnya nilai Asymp sig (2-tailed) sebesar 0,200>0,05.

4. Uji Heteroskedastisitas

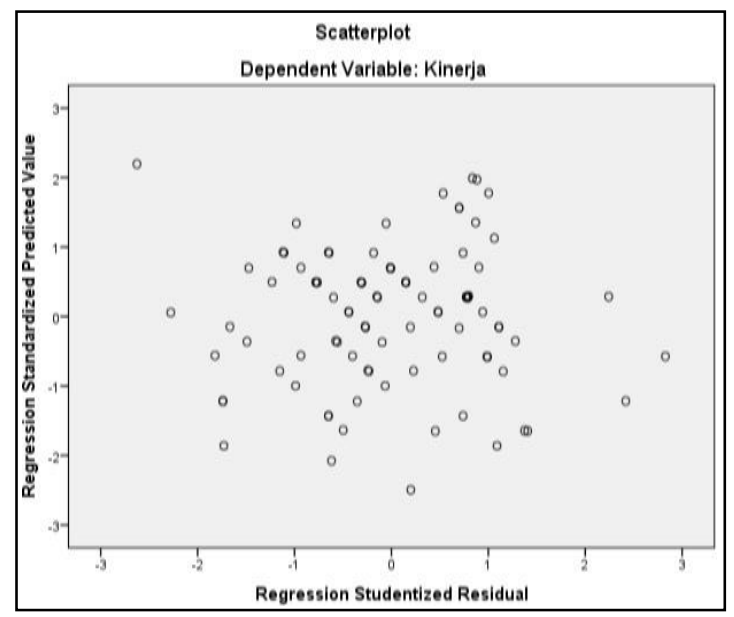

Gambar 4. Hasil Uji Heteroskedastisitas

Gambar 4 scatterplot diatas terlihat titik-titik menmyebar secara acak tidak membentuk suatu pola tertentu yang jelas,tersebar baik diatas maupun dibawah angkat 0 pada sumbu Y maka dapat disimpulkan tidak terjadi heteroskedastisitas pada model regresi,sehingga model regresi layak untuk memprediksi Y. 
eCo-Buss

5. Uji Multikolinearitas

Tabel 3. Hasil Uji Multikolinearitas

\begin{tabular}{|c|c|}
\hline Model & $\begin{array}{c}\text { Collinearity } \\
\text { Statistics } \\
\text { Tolerance VIF } \\
\end{array}$ \\
\hline $\begin{array}{l}1 \text { (Constant) } \\
\text { Fasilitas } \\
\text { kerja } \\
\end{array}$ & \begin{tabular}{ll|l}
0.642 & 1.557
\end{tabular} \\
\hline Pelatihan & \begin{tabular}{l|l}
0.630 & 1.586 \\
\end{tabular} \\
\hline Kedisiplinan & $0.787 \quad 1.271$ \\
\hline
\end{tabular}

Tabel 3 hasil uji multikolinearitas ketiga variabel independen nilai perhitungan tolerance $>0,1$ yakni fasilitas kerja 0,642>0.1,pelatihan 0,630>0.1 dan disiplin kerja 0,787>0,1 sedangkan hasil perhitungan VIF $<10$ sebesar Fasilitas kerja 1,557<10,Pelatihan $1,586<10$ dan Kedisiplinan $1,271<10$. Dapat disimpulkan bahwa tidak terjadi multikolinearitas diantara variabel independen dalam model regresi.

6. Uji Autokorelasi

Tabel 4. Hasil Uji Autokorelasi

\begin{tabular}{|c|c|c|}
\hline Model & $\mathbb{R}$ & R Square Durbin-Watson \\
\hline$T$ & $0.618^{a}$ & 0.3822 .235 \\
\hline $\begin{array}{l}\text { a. Pre } \\
\text { kerja, } \\
\text { b. Dep }\end{array}$ & $\begin{array}{l}\text { dictors: ( } \\
\text { Pelatihar } \\
\text { jendent }\end{array}$ & $\begin{array}{l}\text { Constant), Kedisiplinan, Fasilitas } \\
\text { V ariable: Kinerja }\end{array}$ \\
\hline
\end{tabular}

Tabel 4 yaitu hasill uji autokorelasi dapat dilihat hasil Durbin-Watson (DW) sebesar 2,235, dengan $(n)=92$, jumlah variabel independen $3(K=3)$ maka didapatkan nilai $\mathrm{DU}<\mathrm{DW}<4$ DU sebesar $1,7285<2,235<2,2715$, maka dapat disimpulkan bahwa pada uji ini tidak terjadi autokorelasi.

7. Uji Signifikansi Simultan (Uji Statistik F )

Tabel 5. Hasil Uji Statistik F

\begin{tabular}{|l|l|l|l|}
\hline \multicolumn{3}{|c|}{ ANOVA $^{a}$} \\
\hline \multirow{2}{|c|}{ Model } & $F$ & Sig \\
\hline \multirow{3}{*}{1} & Regression & 18.129 & $0.000^{b}$ \\
\cline { 2 - 4 } & Residual & & \\
\cline { 2 - 4 } & Total & & \\
\cline { 2 - 4 } & $\begin{array}{l}\text { a. Dependent Variable: Kinerja } \\
\text { b. Predictors: (Constant), Kedisiplinan, Fasilitas } \\
\text { kerja, Pelatihan }\end{array}$ & & \\
\hline
\end{tabular}

Tabel 5 hasil pengujian koefisien determinasi $\left(\mathrm{R}^{2}\right)$ sebesar 0.382 artinya $38.2 \%$ fasilitas kerja, pelatihandan disiplin kerja berpengaruh terhadap kinerja karyawan PT. Centrayasa Megatamacipta sedangkan sisanya sebesar $61,8 \%$ dipengaruhi faktor lain yang belum diteliti 
8. Uji T ( Pengujian Secara Parsial )

Tabel 6. Hasil Uji T

\begin{tabular}{|l|l|l|l|l|l|l|}
\hline \multicolumn{2}{|c|}{ Model } & \multicolumn{2}{l|}{$\begin{array}{l}\text { Unstandardized } \\
\text { Coefficients }\end{array}$} & $\begin{array}{l}\text { Standardize } \\
d \\
\text { Coefficients }\end{array}$ & & \\
\hline & & $B$ & Std.Eror & Beta & $t$ & Sig \\
\hline 1 & (Constant) & 1274 & 3.720 & & 3.415 & 0.001 \\
\hline & Fasil itas kerja & 0.003 & 0.068 & 0.004 & 0.041 & 0.968 \\
\hline & Pelat ihan & 0.359 & 0.113 & 0.336 & 3.183 & 0.002 \\
\hline & Disiplin Kerja & 0.364 & 0.087 & 0.394 & 4.170 & 0.000 \\
\hline
\end{tabular}

a. Dependent Variable: Kinerja

Tabel 6 hasil pengujian secara parsial:

a. Variable fasilitas kerja (X1) diperoleh nilai t-hitung lebih kecil dari t-tabel $0,041<$ 1,987,pada signifikansi $0,968>0,05$ dengan demikian disimpulkan bahwa hipotesis $\mathrm{H} 1=$ 0 diterima dan hipotesis $\mathrm{H} 1 \neq 0$ ditolak yang berarti tidak terdapat pengaruh fasilitas kerja (X1) terhadap Kinerja karyawan (Y) PT. Centrayasa Megatamacipta.

b. Variabel pelatihan (X2) diperoleh nilai t-hitung lebih besar dari t-tabel 3,183>1.987 pada signifikasi $0,002<0,05$ dengan demikian disimpulkan bahwa hipotesis $\mathrm{H} 2=0$ ditolak dan hipotesis $\mathrm{H} 2 \neq 0$ diterima yang berarti terdapat pengaruh yang signifikan pelatihan kerja (X2) terhadap kinerja karyawan (Y) PT. Centrayasa Megatamacipta

c. Variabel disiplin kerja (X3) diperoleh nilai t-hitung lebih besar dari t-tabel 4,170>1.987 pada signifikansi 0,000 <0,05, dengan demikian dapat disimpulkan bahwa hipotesis $\mathrm{H} 3=$ 0 ditolak dan hipotesis $\mathrm{H} 3 \neq 0$ diterima yang berarti terdapat pengaruh disiplin kerja (X3) terhadap kinerja karyawan (Y) PT.Centrayasa Megatama

6. Analisa Regresi Linier Berganda

Tabel 7. Hasil Uji Analisa Regresi Linier Berganda

\begin{tabular}{|l|l|r|r|}
\hline \multicolumn{2}{|c|}{ Model } & \multicolumn{2}{c|}{ Unstandardized Coefficients } \\
\hline & B & \multicolumn{2}{|c|}{ Std. Error } \\
\hline 1 & Constant & 12,704 & 3,720 \\
\hline 2 & Fasilitas kerja &, 003 &, 068 \\
\hline 3 & Pelatihan &, 359 &, 113 \\
\hline 4 & Disiplin Kerja &, 364 &, 087 \\
\hline
\end{tabular}

a. Variabel Dependent Kinerja Karyawan

Dari tabel 7 diperoleh persamaan regresi sebagai berikut:

$\mathrm{Y}=\mathrm{a}+\mathrm{b} 1 . \mathrm{X} 1+\mathrm{b} 2 \cdot \mathrm{X} 2+\mathrm{b} 3 . \mathrm{X} 3+\mathrm{e}$

$\mathrm{Y}=12,704+0,003 \mathrm{X} 1+0,359 \mathrm{X} 2+0,364 \mathrm{X} 3+\mathrm{e}$

a. Konstanta $=12,704$

Jika konstanta sebesar 12,704 menyatakan bahwa variabel independen dianggap konstan, maka rata-rata kinerja karyawan sebesar 12,704.

b. Koefisien regresi fasilitas kerja $(\mathrm{X} 1)=0,003$

Setiap kenaikan fasilitas kerja satu satuan maka mengakibatkan kenaikan kinerja karyawan PT. Centrayasa Megatama sebesar 0,003 satuan.

c. Koefisien regresi Pelatihan $(\mathrm{X} 2)=0,359$

Setiap kenaikan fasilitas kerja satu satuan maka mengakibatkan kenaikan kinerja karyawan PT. Centrayasa Megatama sebesar 0,359. 
d. Koefisien regresi Kedisiplinan $(X 3)=0,364$

Setiap kenaikan fasilitas kerja satu satuan maka mengakibatkan kenaikan kinerja karyawan PT. Centrayasa Megatama sebesar 0,364

\section{Kesimpulan}

Kinerja karyawan PT. Centrayasa Megatama tidak dipengaruhi oleh fasilitas kerja yang dimiliki namun pelatihan kerja yang dilakukan dan disiplin kerja yang tinggi akan berpengaruh positif dan signifikan terhadap peningkatan kinerja di PT. Centrayasa Megatamacipta.

\section{Daftar Referensi}

Fred, J. W., \& Brigham, E. (2011). Essential of Financial Management: Dasar-dasar Manajemen Keuangan. Jakarta: Salemba Empat.

Ghozali, I. (2016). Aplikasi Multivariate Dengan Program IBM SPSS 23. Semarang: Universitas Diponegoro.

Hasibuan. (2014). Manajeman Sumber Daya Manusia”, Cetakan 2. Bandung: CV.Pustaka Setia.

Sitio, R. (2019). Pengaruh Umur dan Ukuran Perusahaan Terhadap ROE (Return On Equity) Studi pada Perusahaan Jasa Sektor Poperti dan Real Estate yang Terdaftar di BEI Periode 2011-2017. Equilibrium: Jurnal Ekonomi-Manajemen-Akuntansi, 167.

Nurhayati, Eti 2018, "Manajemen Sumber Daya Manusia", Cetakan 1, Penerbit Yrama Widya, Bandung.

Priyastama, Romie, 2017, "Buku Sakti Kuasai SPSS", Cetakan 1, Penerbit Star UP, Yogyakarta. Prof. Dr. Wibowo,S.E.,M.Phil, Edisi kelima (2016), "Manajemen Kinerja". Cetakan 11, Penerbit Rajawali Pers, Jakarta. 